Supporting Information

\title{
Interconnection of the Antenna Pigment 8-HDF and Flavin Facilitates Red-Light Reception in a Bifunctional Animal-like Cryptochrome
}

\author{
Sabine Oldemeyer ${ }^{\mathrm{a}, \mathrm{b}^{*}}$, Andrew Z. Haddad ${ }^{\mathrm{c}}$, Graham R. Fleming ${ }^{\mathrm{a}, \mathrm{b}, \mathrm{d}}$
}

\author{
Author affiliations: \\ ${ }^{a}$ Department of Chemistry, University of California, Berkeley, California 94720, United \\ States \\ ${ }^{\mathrm{b}}$ Molecular Biophysics and Integrated Bioimaging Division, Lawrence Berkeley National \\ Laboratory, Berkeley, California 94720, United States \\ ${ }^{\mathrm{c}}$ Energy Technologies Area, Lawrence Berkeley National Laboratory, Berkeley, \\ California 94720, United States. \\ ${ }^{\mathrm{d}}$ Kavli Energy Nanoscience Institute, Berkeley California 94720, United States
}

\footnotetext{
*Corresponding author:

Sabine Oldemeyer

E-Mail: soldemeyer@lbl.gov
} 


\section{Material and Methods}

Size exclusion chromatography was performed using an ÄKTA micro chromatography system with a Superdex 200 Increase 10/300 GL column (GE Healthcare) at room temperature. Prior to the chromatography, aCRY 8 -HDF aliquots with a volume of 200 $\mu \mathrm{L}$ were filtrated through a $0.22 \mu \mathrm{m}$ filter using Durapore Ultrafree filters (Merck Millipore) centrifuged at $10,000 \times \mathrm{g}$ for $5 \mathrm{~min}$ at $4{ }^{\circ} \mathrm{C}$. For equilibration and elution, 50 $\mathrm{mM}$ phosphate buffer with $200 \mathrm{mM} \mathrm{NaCl}$ at $\mathrm{pH} 7.0$ were used.

\section{Results}

\section{Changes in the Hydrogen Bonding Network of Asn 395}

The experimental double difference spectrum of aCRY $\bullet$-HDF minus aCRY shows a prominent positive band at $1695 \mathrm{~cm}^{-1}$ that is assigned to a change in the hydrogen bonding structure of the asparagine N395 in response to $\mathrm{FADH}^{-}$formation (Table S5), ${ }^{1,2}$ which differs between aCRY 8 -HDF and aCRY. It can be ruled out that the band originates from 8-HDF since no equivalent band is present in the calculated 8-HDF spectra. The small shoulder at $1684 \mathrm{~cm}^{-1}$ represents the negative counterpart in agreement with previous studies. ${ }^{1,2}$ The small magnitude of the mode is due to the overlay of the negative band at $1684 \mathrm{~cm}^{-1}$ in the aCRY 8 -HDF spectrum with the positive band in the aCRY spectrum at $1686 \mathrm{~cm}^{-1}$ (Fig. 4A).

\section{Assignment of Vibrational Modes Arising from Changes in the Hydrogen Bonding Network of Tyrosine 373:}

In the double difference spectrum of aCRY $\bullet$-HDF minus aCRY the bands at $1400 \mathrm{~cm}^{-1}$, $1281 \mathrm{~cm}^{-1}, 1225 \mathrm{~cm}^{-1}$ and $1215 \mathrm{~cm}^{-1}$ are assigned to the tyrosine residue 373 (Tab. S5). The bands at $1400 \mathrm{~cm}^{-1}$ and $1281 \mathrm{~cm}^{-1}$ originate from the $v 7$ 'a $\mathrm{CO}$ stretching and $\delta \mathrm{CO}$ bending vibration, respectively, of the tyrosyl radical. ${ }^{3}$ Their appearance in the spectrum is due to a faster decay of the TyrO• in aCRY $\bullet$ - $\mathrm{HDF}$ as observed in the millisecond time 
resolved UV-vis experiments $(2.0 \mathrm{~s}$ in aCRY $\bullet$-HDF vs. $2.6 \mathrm{~s}$ in aCRY). The mode at $1281 \mathrm{~cm}^{-1}$ also contains contributions from the $v 7^{\prime}$ a $\mathrm{CO}$ stretching vibration of the TyrOH acting as a hydrogen bond donor in agreement with calculations $\left(1274 \mathrm{~cm}^{-1}\right)^{4}$ and experimental data $\left(1263 \mathrm{~cm}^{-1}\right)^{3-5}$ with a counterpart at $1225 \mathrm{~cm}^{-1}$ for the tyrosine acting as a hydrogen bond acceptor $\left(1223 \mathrm{~cm}^{-1}\right)^{3}$, indicating changes in the tyrosine hydrogen bonding network in the dark state of aCRY $\bullet$ - HDF as compared to aCRY. The band at $1215 \mathrm{~cm}^{-1}$ arises from an up-shifted $\delta \mathrm{CO}$ bending mode of the $\mathrm{TyrOH}$ phenol group functioning as a hydrogen bond donor $\left(1222 \text { and } 1192 \mathrm{~cm}^{-1}\right)^{3}$. No negative counterpart is present, since it is found outside the analyzed range at $1168 \mathrm{~cm}^{-13}$. All described bands and their assignments are listed in Table S5.

\section{Discussion}

In a previous study, the analysis of the red-light-response of aCRY in the millisecond to second time regime revealed a surprisingly long lived of $\mathrm{TyrO} \cdot$ with $\tau=$ $2.6 \mathrm{~s}$ decaying concomitantly with FADH $\bullet{ }^{6}$ The stabilization of the TyrO $\bullet$ was rationalized by a $\pi-\pi$ stacking with the adjacent tryptophan $322^{3}$. In this study, a lifetime of $2.0 \mathrm{~s}$ for $\mathrm{TyrO} \bullet$ and $\mathrm{FADH} \bullet$, respectively, in aCRY 8 -HDF was found, which is $23 \%$ shorter, than in aCRY. This finding is in agreement with the results of the long term kinetics and FTIR data supporting the theory of structural changes in the FAD binding pocket due to the presence of $8-\mathrm{HDF}$ favoring FADH•. The slight shortening of the lifetime of TyrO is not due to an alteration in the $\pi-\pi$ stacking with W322 since that would result in a more drastic shortening of the radical's lifetime as shown in the W322F mutant where the exchange of the tryptophan to a phenylalanine led to a shortening of the TyrO• lifetime to under $40 \mathrm{~ms} .{ }^{3}$ Instead, the slightly faster decay indicates changes in the 
hydrogen bonding network close to the reactive tyrosine as supported by the FTIR difference spectra. Here, the characteristic TyrOH vibrations $v 7$ 'aCO and $\delta \mathrm{COH}$ in aCRY $\bullet$ - HDF are found at 1281 and $1215 \mathrm{~cm}^{-1}$, respectively. These frequencies are characteristic for a $\mathrm{TyrOH}$ acting as a hydrogen bond donor to a carbonyl oxygen as shown by calculations ${ }^{4}$ and experimental data of the aCRY-C482A mutant (1223 and $\left.1168 \mathrm{~cm}^{-1}\right)^{3}$, hinting towards a comparable hydrogen bonding network in aCRY $\bullet 8$-HDF and aCRY-C482A. This assumption is in line with the position of the $v 7$ 'aCO marker band of TyrO • found at $1396 \mathrm{~cm}^{-1}$ in aCRY•8-HDF at the same frequency as in aCRYC482A. The position of the band at very low frequencies also proofs that the $\pi-\pi$ staking between Y373 and W322 is still intact in aCRY $\bullet$-HDF. 


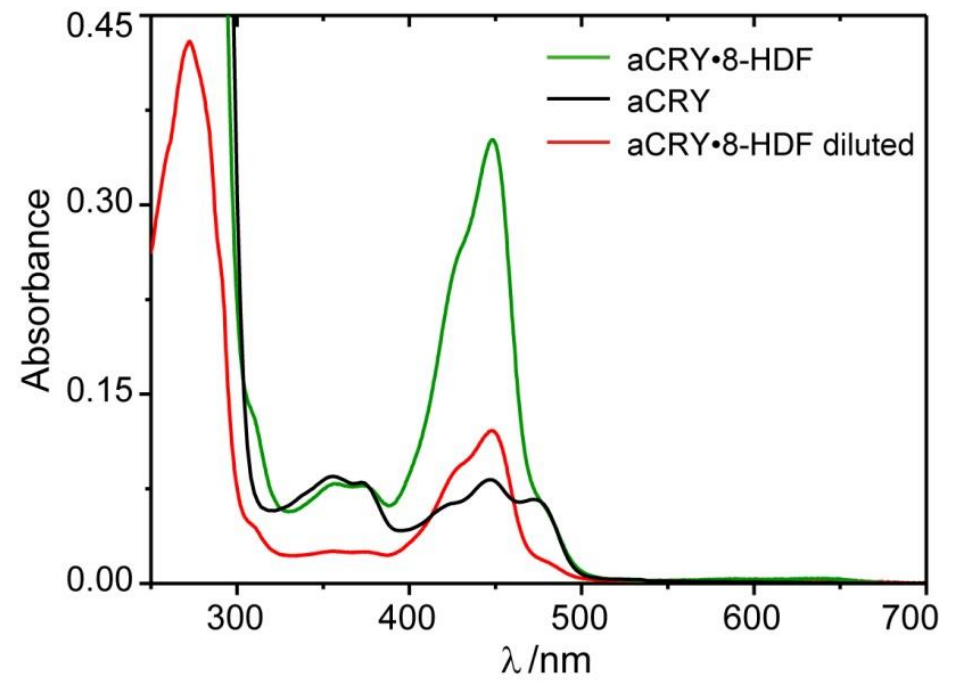

Figure S1. Absorbance spectra of aCRY $\bullet$-HDF after an additional size exclusion chromatography (green), a 3-fold dilution of that sample (red) and aCRY (black). The spectra were used to calculate the chromophore occupancy of the aCRY $\bullet$-HDF sample after the additional purification step. The spectrum of aCRY was used to determine the flavin content in aCRY $\bullet 8$-HDF and the dilution was used to calculate the portion of absorption by the protein backbone at $280 \mathrm{~nm}$. The chromophore occupancy of the sample was determined to be $92 \%$ and $93 \%$ for FAD and 8-HDF, respectively. 


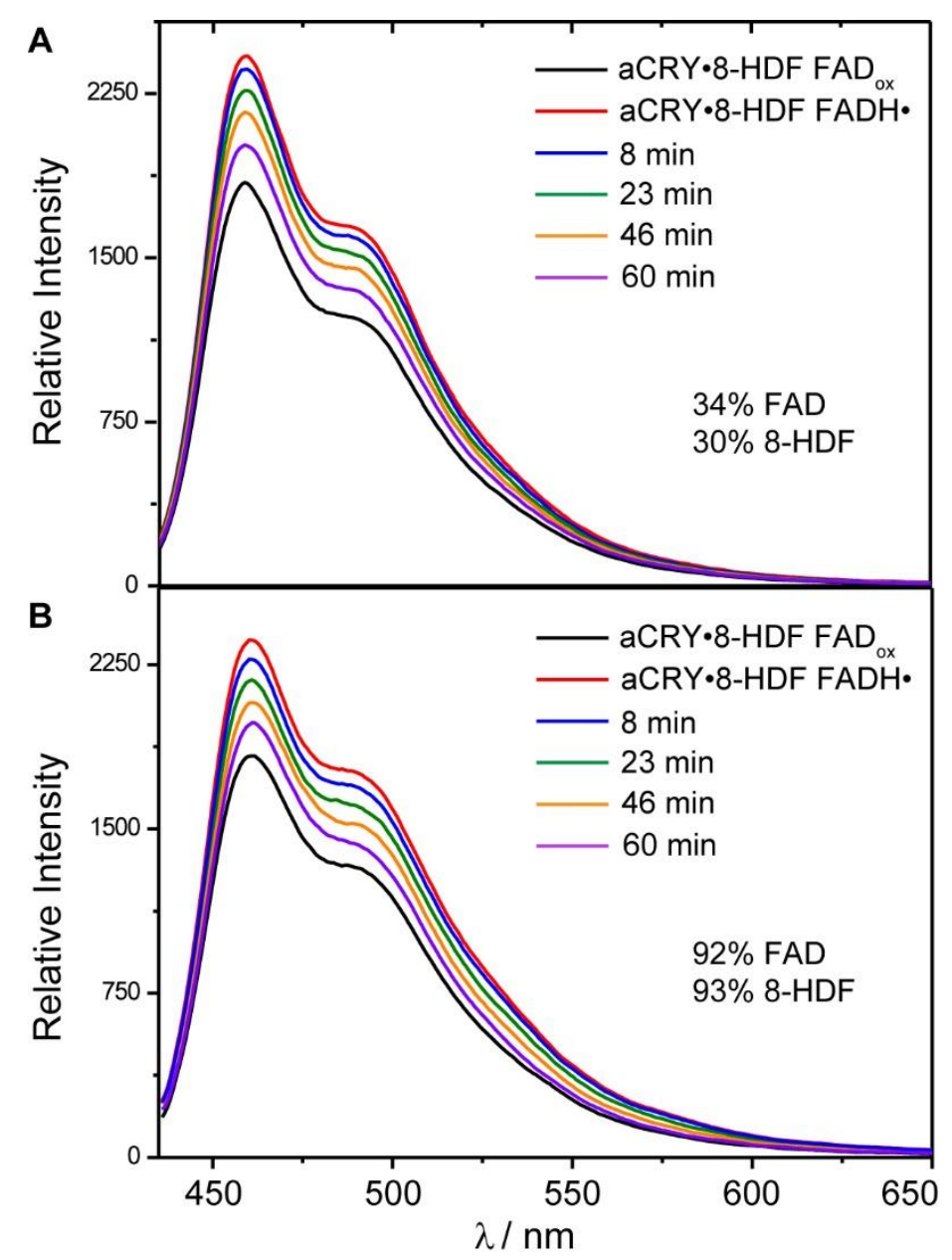

Figure S2. Fluorescence emission spectra of aCRY $\bullet$-HDF with $34 \%$ and $30 \%$ FAD and 8-HDF occupancy (A), respectively, are compared to samples with $92 \%$ and $93 \%$ FAD and 8-HDF occupancy (B). The samples were excited at $432 \mathrm{~nm}$ with a detection time of $0.02 \mathrm{~s}$. After illumination of aCRY $\bullet$-HDF with $\mathrm{FAD}_{\text {ox }}$ for $10 \mathrm{~s}$ at $473 \mathrm{~nm}$ aCRY $\bullet 8-\mathrm{HDF}$ with $\mathrm{FADH} \bullet$ is formed. The fluorescence emission rises in both samples by $30 \%$ upon conversion from $\mathrm{FAD}_{\text {ox }}$ (black) to $\mathrm{FADH} \bullet$ (red). Over a time course of 60 min in both samples the emission decreases slowly implying a mutual decay with FADH•. 


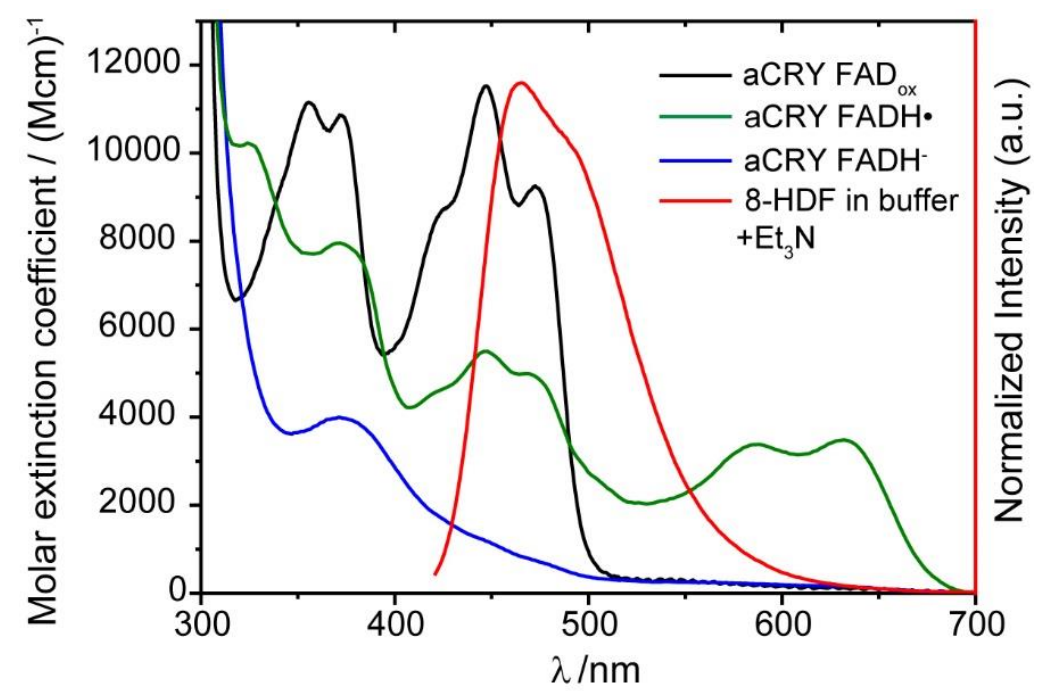

Figure S3. The overlap integral used to calculate the Förster efficiency was determined using the molar extinction coefficient spectra of aCRY carrying FAD ox (black), FADH• (green), and $\mathrm{FADH}^{-}$(blue) and the normalized emission spectrum of 8-HDF (red) solved in phosphate buffer with $0.1 \% \mathrm{v} / \mathrm{v} \mathrm{Et}_{3} \mathrm{~N}$. 


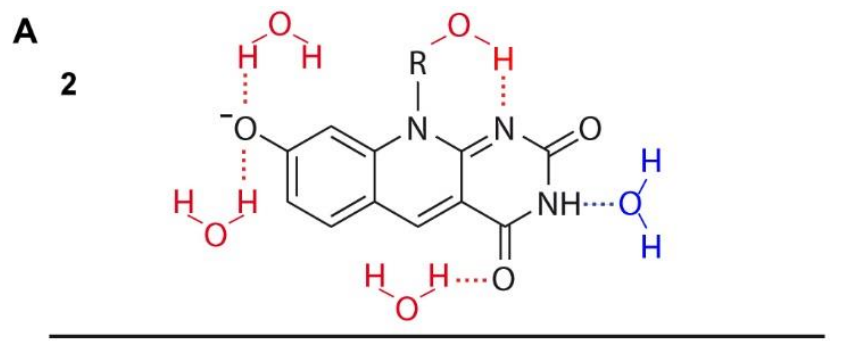

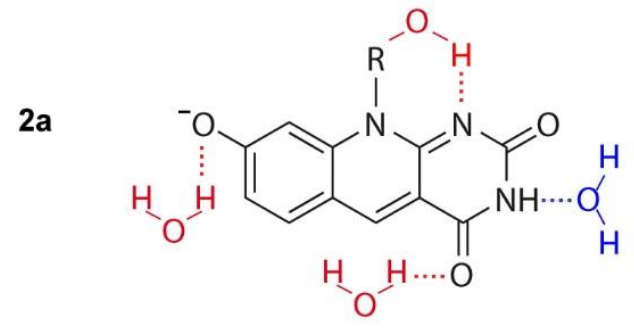

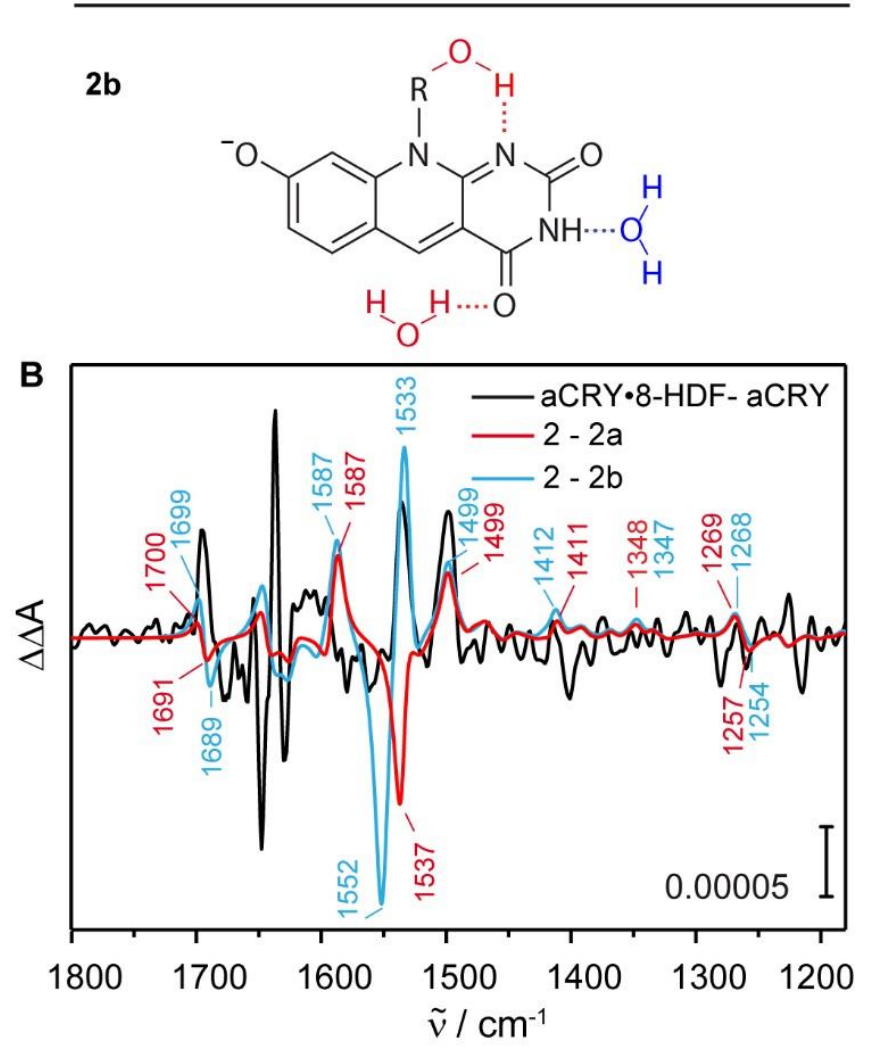

Figure S4. (A) Chemical structures of the 8-HDF anion tested in the DFT calculations as possible models for 8 -HDF in aCRY $\bullet$-HDF before and after illumination. Model 2 shows the deprotonated 8-hydroxyl group as the acceptor of two hydrogen bonds as assigned to the state after red-light-illumination. Model 2a shows the 8-HDF anion with only one hydrogen bond at the 8-hydroxyl group whereas in model $\mathbf{2 b}$, this group is not hydrogen bonded at all. Model $2 \mathrm{a}$ and $\mathrm{b}$ were tested as possible dark states. (B) The double difference spectrum of aCRY $\bullet$-HDF minus aCRY at $2 \mathrm{~s}$ (black) is compared to results of the quantum chemical calculations (red and blue). Signals originate from aCRY 
and model $2 \mathbf{a}$ or $\mathbf{b}$ (negative) and aCRY 8 -HDF and model $\mathbf{2}$ (positive). In both difference spectra negative bands are present at $1552 \mathrm{~cm}^{-1}$ and $1537 \mathrm{~cm}^{-1}$ that are not present in the experimental data, ruling these models out as possible dark states. 


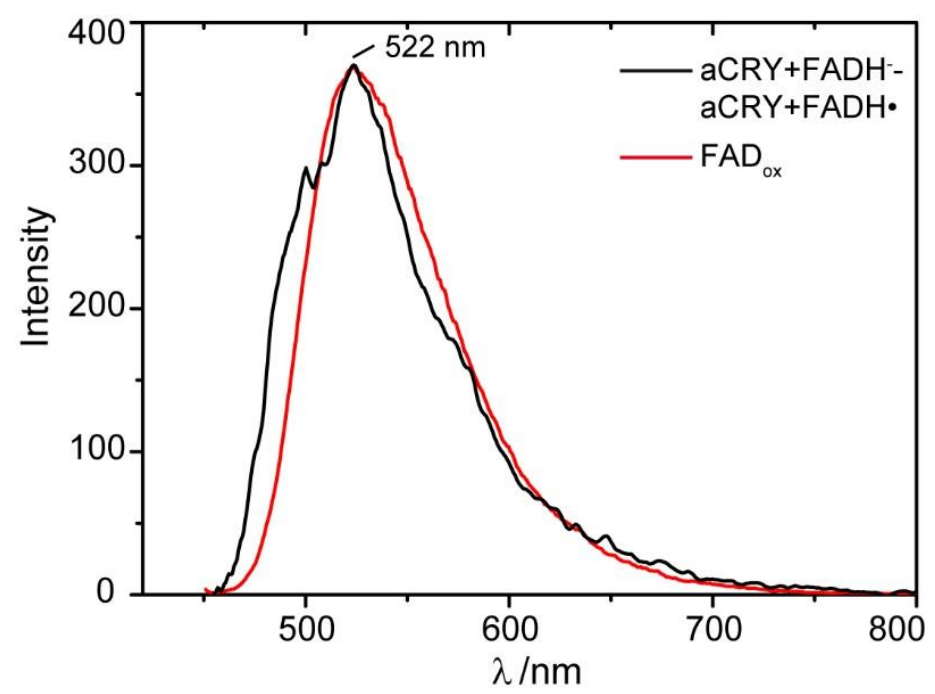

Figure S5. The difference spectrum of the scaled fluorescence emission of aCRY $\bullet$ - HDF with $\mathrm{FADH}^{-}$minus aCRY $\bullet 8$-HDF with FADH• (black) is compared to a spectrum of oxidized flavin solved in phosphate buffer (red). Both spectra show very similar band shape and an identical absorbance maximum at $522 \mathrm{~nm}$, confirming the difference in the spectra to originate from free flavin, released from aCRY upon generation of $\mathrm{FADH}^{-}$. 


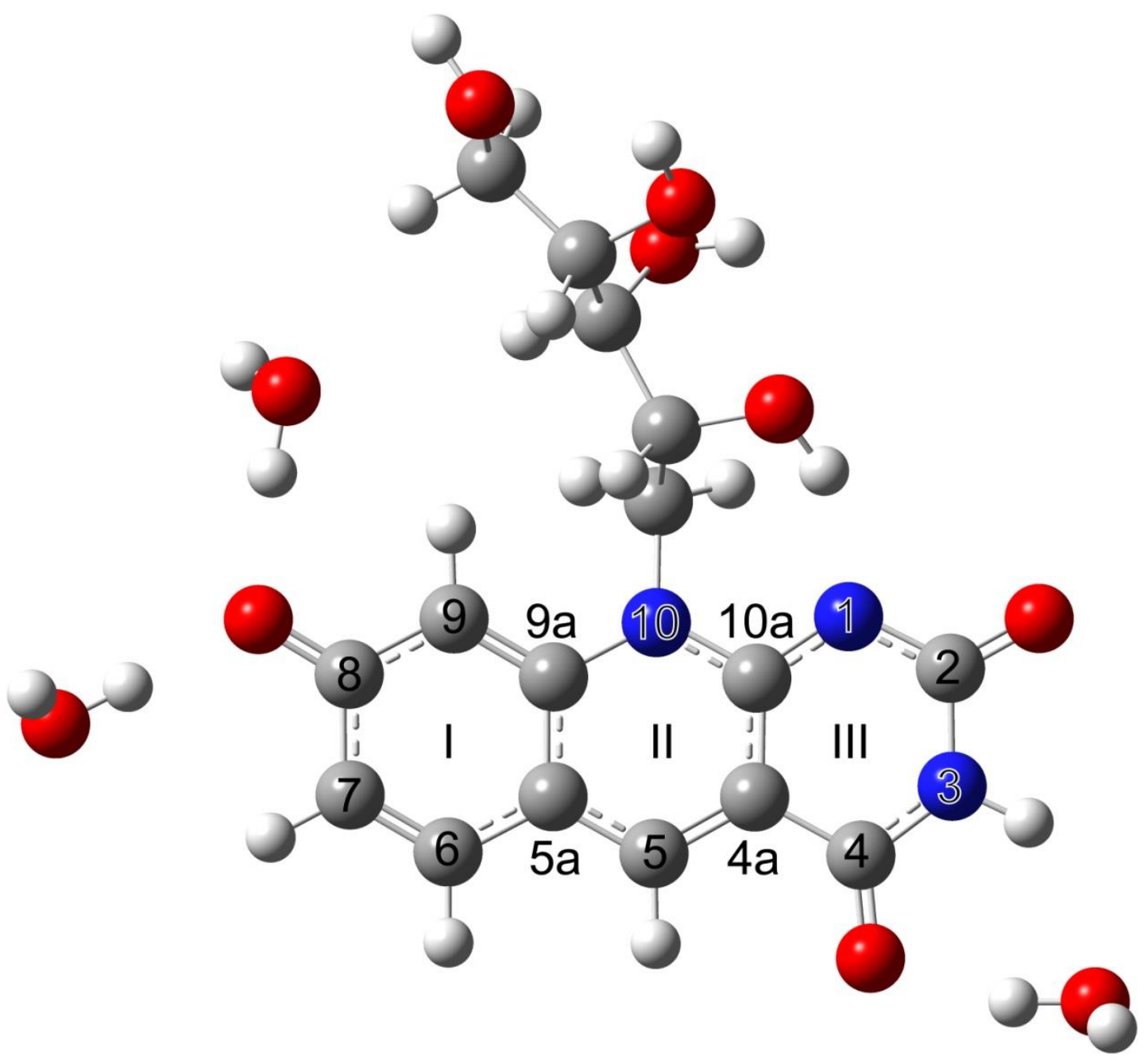

Figure S6. Optimized structure of the deprotonated 8-hydroxy-5-deazaflavin with water molecules used to mimic the hydrogen bonding network in the protein binding pocket. 
Table S1: Parameters used to calculate the Förster resonance energy transfer efficiencies $\mathrm{E}$ for aCRY $\bullet$ - $\mathrm{HDF}$ with 8 - HDF acting as the donor to either $\mathrm{FAD}_{\mathrm{ox}}, \mathrm{FADH} \bullet$ or $\mathrm{FADH}^{-}$ as receptors. $\Phi_{\mathrm{D}}$ represents the quantum yield of the donor chromophore in absence of the acceptor, taken from ref 7. $n$ is the refractive index for a protein buffer. ${ }^{8}$ The center-tocenter distance of the donor-acceptor pair is given as $r$, which was derived from the crystal structure. ${ }^{9} \kappa^{2}$ is the orientation factor of the chromophores, representing the angle of the transition dipole moments of donor and acceptor towards each other. Here a value calculated for $\mathrm{FADH}^{-}$and 8-HDF in the (6-4) photolyase of A. nidulans ${ }^{10}$ was chosen. $J(\lambda)$ is the overlap integral of the molar extinction coefficient of the acceptor in $\mathrm{nm}^{4} \mathrm{M}^{-}$ ${ }^{1} \mathrm{~cm}^{-1}$ and the normalized emission spectrum of the donor in absence of the acceptor. $\mathrm{R}_{0}$ is the distance at which the transfer efficiency between the chromophores is $50 \%$.

\begin{tabular}{|c|c|c|c|c|c|c|c|}
\hline 8-HDF to & $\Phi_{\mathrm{D}}$ & $n$ & $\mathrm{r}(\AA)$ & $\kappa^{2}$ & $J(\lambda)\left(\mathrm{nm}^{4} / \mathrm{Mcm}\right)$ & $\mathrm{R}_{0}(\AA)$ & $E$ \\
\hline FAD $_{\text {ox }}$ & 0.65 & 1.39 & 17.4 & 1.82 & $2.44710^{14}$ & 43.6 & 0.996 \\
\hline FADH• & 0.65 & 1.39 & 17.4 & 1.82 & $3.04410^{14}$ & 45.2 & 0.997 \\
\hline FADH $^{-}$ & 0.65 & 1.39 & 17.4 & 1.82 & $3.21910^{13}$ & 31.1 & 0.970 \\
\hline
\end{tabular}


Table S2. Assignment of the FTIR difference bands (frequencies in $\mathrm{cm}^{-1}$ ) of aCRY $\bullet 8$ $\mathrm{HDF}$ and aCRY after the conversion of FADH• to FADH ${ }^{-}$.

\begin{tabular}{|c|c|c|c|c|}
\hline \multicolumn{2}{|l|}{ positive } & \multicolumn{2}{|l|}{ negative } & \multirow[t]{2}{*}{ assignment } \\
\hline aCRY॰8-HDF & aCRY & aCRY•8-HDF & aCRY & \\
\hline 1697 & 1686 & & & Asn $^{1}$ \\
\hline & & 1684 & 1693 & Asn ${ }^{1}$ \\
\hline \multirow[t]{3}{*}{1675} & 1675 & & & turn elements, amide $\mathrm{I}^{1,11}$ \\
\hline & & 1663 & 1663 & $\mathrm{vC}_{4} \mathrm{O}^{a 1}$ \\
\hline & & 1652 & 1652 & $\mathrm{vC}_{2} \mathrm{O}^{1}$ \\
\hline 1623 & 1622 & & & flavin $\mathrm{CO}^{1}$ \\
\hline \multirow[t]{2}{*}{1557} & 1556 & & & falvin + amide $\|^{1}$ \\
\hline & & 1534 & 1534 & $\begin{array}{l}\text { 8-HDF }{ }^{b}, \\
v C_{10 \mathrm{a}} \mathrm{N}_{1}, v C C \text { ring I } \\
\end{array}$ \\
\hline 1514 & 1514 & & & flavin $^{1}$ \\
\hline 1496 & & & & $8-\mathrm{HDF}^{\mathrm{c}}$ \\
\hline 1396 & 1396 & & & $\begin{array}{l}\text { flavin, } \delta(\mathrm{NH})^{12} \\
\text { TyrO }^{3}\end{array}$ \\
\hline 1351 & 1348 & & & flavin $^{1}$ \\
\hline 1298 & 1296 & & & $v\left(\mathrm{C}-\mathrm{N}_{5}\right)^{1}$ \\
\hline
\end{tabular}

${ }^{a} v=$ stretching mode, ${ }^{b}$ this study 
Table S3. Assignment of negative bands in the FTIR double difference spectrum of aCRY $\bullet$-HDF minus aCRY. Calculated frequencies (scaled by 0.98), intensities and potential energy distributions (PED) of the normal modes of model $\mathbf{1}$ for the 8-HDF are included. Potential energy distributions (PED) for the normal modes were calculated with a home-written algorithm in Matlab (The Mathworks, Natick, MA, USA) from the internal force constants and amplitudes of internal modes determined by Gaussian $16^{13}$. Modes with more than $90 \%$ contribution from water molecules in the PED were not included in the further analysis. For simplification, only modes with an intensity $>5 \%$ of the maximum intensity are shown. For the PED, a cutoff of $1 \%$ was applied.

\begin{tabular}{|c|c|c|c|c|c|c|c|}
\hline $\begin{array}{l}\text { Experiment/ } \\
\mathrm{cm}^{-1} \\
\mathrm{aCRY} \cdot 8-\mathrm{HDF}\end{array}$ & $\begin{array}{l}\text { Discrepancy } \\
\text { to } \\
\text { calculation }\end{array}$ & $\begin{array}{l}\text { Theory/ } \\
\text { cm }^{-1}\end{array}$ & No. & Intensity & $\begin{array}{l}\text { PED } \\
\text { component } \\
\# 1\end{array}$ & $\begin{array}{l}\text { PED } \\
\text { component } \\
\text { \#2 }\end{array}$ & $\begin{array}{l}\text { PED } \\
\text { component } \\
\text { \#3 }\end{array}$ \\
\hline & & 1183 & 88 & 212 & $50 \%$ & $22 \%$ & $9 \%$ \\
\hline & & & & & $\delta \mathrm{C}_{8} \mathrm{OH}$ & $v C C$ ring $I^{a}$ & $\delta \mathrm{CCH}$ ring $\mathrm{I}^{b}$ \\
\hline & & 1209 & 90 & 69 & $34 \%$ & $13 \%$ & $11 \%$ \\
\hline & & & & & $v \mathrm{CN}$ ring III & $\delta \mathrm{COH}$ chain & $v \mathrm{CN}$ ring II \\
\hline \multirow[t]{14}{*}{1260} & 10 & 1250 & 94 & 437 & $23 \%$ & $22 \%$ & $17 \%$ \\
\hline & & & & & $v \mathrm{C}_{8} \mathrm{O}$ & $\mathrm{vCC}$ ring $\mathrm{I}$ & $v C C$ ring II \\
\hline & & 1253 & 95 & 131 & $43 \%$ & $15 \%$ & $7 \%$ \\
\hline & & & & & $\delta \mathrm{COH}$ chain & $v \mathrm{CN}$ ring II & $v \mathrm{C}_{8} \mathrm{O}$ \\
\hline & & 1354 & 101 & 58 & $55 \%$ & $16 \%$ & $13 \%$ \\
\hline & & & & & $\delta \mathrm{COH}$ chain & $\begin{array}{l}\tau \mathrm{CCOH} \\
\text { chain }^{c}\end{array}$ & $v C C$ chain \\
\hline & & 1405 & 107 & 156 & $28 \%$ & $27 \%$ & $15 \%$ \\
\hline & & & & & $\mathrm{vCC}$ ring $\mathrm{I}$ & $\mathrm{vCN}$ ring III & $v C C$ ring II \\
\hline & & 1456 & 110 & 145 & $47 \%$ & $15 \%$ & $12 \%$ \\
\hline & & & & & $\begin{array}{l}\delta \mathrm{CNH} \text { ring } \\
\text { III }\end{array}$ & $\mathrm{vC}_{2} \mathrm{O}$ & $v \mathrm{C}_{4} \mathrm{O}$ \\
\hline & & 1470 & 111 & 97 & $27 \%$ & $17 \%$ & $14 \%$ \\
\hline & & & & & $\mathrm{vCN}$ ring II & $\mathrm{vCC}$ ring $\mathrm{I}$ & $\delta \mathrm{C}_{8} \mathrm{OH}$ \\
\hline & & 1506 & 113 & 76 & $28 \%$ & $25 \%$ & $22 \%$ \\
\hline & & & & & $\mathrm{vCC}$ ring I & $\delta \mathrm{CCH}$ ring I & $\mathrm{vCN}$ ring III \\
\hline \multirow[t]{2}{*}{1561} & 18 & 1543 & 114 & 1077 & $47 \%$ & $24 \%$ & $8 \%$ \\
\hline & & & & & $v \mathrm{CN}$ ring III & $\mathrm{vCC}$ ring I & $\delta \mathrm{CCH}$ ring $\mathrm{I}$ \\
\hline \multirow[t]{4}{*}{1579} & 14 & 1565 & 115 & 370 & $44 \%$ & $30 \%$ & $8.1 \%$ \\
\hline & & & & & $v C C$ ring I & $v C C$ ring $I I$ & $\delta \mathrm{C}_{8} \mathrm{OH}$ \\
\hline & & 1606 & 116 & 919 & $38 \%$ & $12 \%$ & $8 \%$ \\
\hline & & & & & $\mathrm{vCC}$ ring II & $v C C$ ring $I$ & $v \mathrm{C}_{2} \mathrm{O}$ \\
\hline \multirow[t]{4}{*}{1676} & 6 & 1682 & 121 & 528 & $62 \%$ & $10 \%$ & $6 \%$ \\
\hline & & & & & $v \mathrm{C}_{2} \mathrm{O}$ & $\mathrm{vCC}$ ringIII & $\mathrm{vCN}$ ring III \\
\hline & & 1694 & 122 & 497 & $64 \%$ & $20 \%$ & \\
\hline & & & & & $v \mathrm{C}_{4} \mathrm{O}$ & $v C N$ ringllI & \\
\hline
\end{tabular}

${ }^{a} v=$ stretching mode, ${ }^{b} \delta=$ bending mode, ${ }^{c} \tau=$ torsional mode 
Table S4. Assignment of positive bands in the FTIR double difference spectrum of aCRY $\bullet$-HDF minus aCRY. Calculated frequencies (scaled by 0.98), intensities and potential energy distributions (PED) of the normal modes of model 2 (Figure S4) for the 8-HDF anion are included. Potential energy distributions (PED) for the normal modes were calculated with a home-written algorithm in Matlab (The Mathworks, Natick, MA, USA) from the internal force constants and amplitudes of internal modes determined by Gaussian $16^{13}$. Modes with more than $90 \%$ contribution from water molecules in the PED were not included in the further analysis. For simplification, only modes with an intensity $>5 \%$ of the maximum intensity are shown. For the PED, a cutoff of $1 \%$ was applied.

\begin{tabular}{|c|c|c|c|c|c|c|c|}
\hline $\begin{array}{l}\text { Experiment/ } \\
\mathrm{cm}^{-1} \\
\text { aCRY॰8-HDF } \\
\text { anion }\end{array}$ & $\begin{array}{l}\text { Discrepancy } \\
\text { to } \\
\text { calculation }\end{array}$ & $\begin{array}{l}\text { Theory } \\
/ \mathrm{cm}^{-1}\end{array}$ & No. & Intensity & $\begin{array}{l}\text { PED } \\
\text { component } \\
\# 1\end{array}$ & $\begin{array}{l}\text { PED } \\
\text { component } \\
\# 2\end{array}$ & $\begin{array}{l}\text { PED } \\
\text { component } \\
\# 3\end{array}$ \\
\hline & & 1145 & 88 & 140 & $49 \%$ & $21 \%$ & $12 \%$ \\
\hline & & & & & $\delta \mathrm{CCH}$ ring $\mathrm{I}$ & $v C C$ ring $I^{a}$ & $v \mathrm{CN}$ ring \\
\hline \multirow[t]{4}{*}{1267} & 1 & 1268 & 96 & 228 & $32 \%$ & $24 \%$ & $15 \%$ \\
\hline & & & & & $\delta \mathrm{CCH}$ ring $\mathrm{I}^{b}$ & $v C C$ ring $I, I I$ & $v \mathrm{CN}$ ring III \\
\hline & & 1347 & 102 & 146 & $30 \%$ & $18 \%$ & $8 \%$ \\
\hline & & & & & $v C C$ ring II & $\delta \mathrm{CCH}$ ring I & $v \mathrm{C}_{8} \mathrm{O}$ \\
\hline \multirow[t]{4}{*}{1414} & 2 & 1412 & 110 & 278 & $37 \%$ & $18 \%$ & $14 \%$ \\
\hline & & & & & $v C C$ ring I & $v \mathrm{CN}$ ring III & $\delta \mathrm{CCH}$ ring $\mathrm{I}$ \\
\hline & & 1467 & 113 & 106 & $22 \%$ & $22 \%$ & $22 \%$ \\
\hline & & & & & $\delta \mathrm{CHH}$ chain & $\delta \mathrm{COH}$ chain & $\tau \mathrm{CH}$ chain $c$ \\
\hline \multirow[t]{2}{*}{1498} & - & 1498 & 116 & 599 & $36 \%$ & $29 \%$ & $8 \%$ \\
\hline & & & & & $v C C$ ring I & $\mathrm{vC}_{8} \mathrm{O}$ & $\delta \mathrm{CCH}$ ring $\mathrm{I}$ \\
\hline \multirow[t]{10}{*}{1535} & 2 & 1533 & 118 & 2076 & $30 \%$ & $23 \%$ & $18 \%$ \\
\hline & & & & & $v \mathrm{CN}$ ring III & $v \mathrm{C}_{8} \mathrm{O}$ & $v C C$ ring $\mathrm{II}, \mathrm{III}$ \\
\hline & & 1588 & 119 & 838 & $58 \%$ & $8 \%$ & $7 \%$ \\
\hline & & & & & $v C C$ ring $I I, I$ & $\delta \mathrm{CCH}$ ring II & $v \mathrm{C}_{8} \mathrm{O}$ \\
\hline & & 1621 & 120 & 268 & $70 \%$ & $10 \%$ & \\
\hline & & & & & $v C C$ ring I, II & $\delta \mathrm{CCH}$ & \\
\hline & & 1645 & 122 & 555 & $58 \%$ & $16 \%$ & $8 \%$ \\
\hline & & & & & $v \mathrm{C}_{4} \mathrm{O}$ & $v C C$ ring III & $\delta \mathrm{CCH}$ ring III \\
\hline & & 1695 & 125 & 691 & $77 \%$ & $7.4 \%$ & $6 \%$ \\
\hline & & & & & $v \mathrm{C}_{2} \mathrm{O}$ & $v \mathrm{C}_{2} \mathrm{~N}$ & $\delta \mathrm{C}_{2} \mathrm{CH}$ \\
\hline
\end{tabular}

\footnotetext{
${ }^{a} v=$ stretching mode, ${ }^{b} \delta=$ bending mode, ${ }^{c} \tau=$ torsional mode
} 
Table S5. Assignment of vibrational frequencies $\left(\mathrm{cm}^{-1}\right)$ in the double difference spectrum of aCRY•8-HDf minus aCRY originating from the residues asparagine 395 (Asn 395) and tyrosine 373 (TyrOH/TyrO• 373).

\begin{tabular}{|c|c|c|c|c|}
\hline positive & & negative & & assignment \\
\hline experiment & literature & experiment & literature & \\
\hline \multirow[t]{5}{*}{1695} & 1693 & & & Asn $395^{1,2}$ \\
\hline & & 1684 & 1686,1687 & Asn $395^{1,2}$ \\
\hline & & 1400 & 1400 & TyrO• $373 v 7^{\prime} \mathrm{aCO}^{a} 3$ \\
\hline & & 1281 & 1280 & TyrO• $373 \delta \mathrm{CO}^{3}$ \\
\hline & & & $1263,1274,1275,1279$ & TyrOH $373 v 7^{\prime}{ }^{\prime} \mathrm{COH}^{3-5,14,15}$ \\
\hline \multirow[t]{2}{*}{1225} & 1223,1232 & & & TyrOH $373 v 7^{\prime} \mathrm{aCOH}^{3,4}$ \\
\hline & & 1215 & $1192,1222,1250,1255$ & TyrOH $373 \delta \mathrm{CO}^{b 3,5}$ \\
\hline
\end{tabular}

${ }^{a} v=$ stretching mode, ${ }^{b} \delta=$ bending mode 


\section{References}

(1) Spexard, M., Thöing, C., Beel, B., Mittag, M., and Kottke, T. (2014) Response of the Sensory Animal-like Cryptochrome aCRY to Blue and Red Light As Revealed by Infrared Difference Spectroscopy, Biochemistry 53, 1041-1050.

(2) Iwata, T., Zhang, Y., Hitomi, K., Getzoff, E. D., and Kandori, H. (2010) Key Dynamics of Conserved Asparagine in a Cryptochrome/Photolyase Family Protein by Fourier Transform Infrared Spectroscopy, Biochemistry 49, 88828891.

(3) Oldemeyer, S., Mittag, M., and Kottke, T. (2019) Time-Resolved Infrared and Visible Spectroscopy on Cryptochrome aCRY: Basis for Red Light Reception, Biophys. J. 117, 490-499.

(4) Takahashi, R., Okajima, K., Suzuki, H., Nakamura, H., Ikeuchi, M., and Noguchi, T. (2007) FTIR study on the hydrogen bond structure of a key tyrosine residue in the flavin-binding blue light sensor TePixD from Thermosynechococcus elongatus, Biochemistry 46, 6459-6467.

(5) Berthomieu, C., Hienerwadel, R., Boussac, A., Breton, J., and Diner, B. A. (1998) Hydrogen bonding of redox-active tyrosine $\mathrm{Z}$ of photosystem II probed by FTIR difference spectroscopy, Biochemistry 37, 10547-10554.

(6) Oldemeyer, S., Franz, S., Wenzel, S., Essen, L. O., Mittag, M., and Kottke, T. (2016) Essential Role of an Unusually Long-lived Tyrosyl Radical in the Response to Red Light of the Animal-like Cryptochrome aCRY, J. Biol. Chem. 291, 1406214071.

(7) Tamada, T., Kitadokoro, K., Higuchi, Y., Inaka, K., Yasui, A., de Ruiter, P. E., Eker, A. P., and Miki, K. (1997) Crystal structure of DNA photolyase from Anacystis nidulans, Nat. Struct. Biol. 4, 887-891.

(8) Kim, S. T., Heelis, P. F., Okamura, T., Hirata, Y., Mataga, N., and Sancar, A. (1991) Determination of rates and yields of interchromophore (folate-->flavin) energy transfer and intermolecular (flavin-->DNA) electron transfer in Escherichia coli photolyase by time-resolved fluorescence and absorption spectroscopy, Biochemistry 30, 11262-11270.

(9) Franz, S., Ignatz, E., Wenzel, S., Zielosko, H., Putu, E. P. G. N., Maestre-Reyna, M., Tsai, M.-D., Yamamoto, J., Mittag, M., and Essen, L.-O. (2018) Structure of the bifunctional cryptochrome aCRY from Chlamydomonas reinhardtii, Nucleic Acids Res. 46, 8010-8022.

(10) Zheng, X., Garcia, J., and Stuchebrukhov, A. A. (2008) Theoretical Study of Excitation Energy Transfer in DNA Photolyase, J. Phys. Chem. B 112, 87248729.

(11) Immeln, D., Pokorny, R., Herman, E., Moldt, J., Batschauer, A., and Kottke, T. (2010) Photoreaction of Plant and DASH Cryptochromes Probed by Infrared Spectroscopy: The Neutral Radical State of Flavoproteins, J. Phys. Chem. B 114, 17155-17161.

(12) Schleicher, E., Hessling, B., Illarionova, V., Bacher, A., Weber, S., Richter, G., and Gerwert, K. (2005) Light-induced reactions of Escherichia coli DNA photolyase monitored by Fourier transform infrared spectroscopy, FEBS J. 272, 1855-1866.

(13) Frisch, M. J., Trucks, G. W., Schlegel, H. B., Scuseria, G. E., Robb, M. A., Cheeseman, J. R., Scalmani, G., Barone, V., Petersson, G. A., Nakatsuji, H., Li, 
X., Caricato, M., Marenich, A. V., Bloino, J., Janesko, B. G., Gomperts, R., Mennucci, B., Hratchian, H. P., Ortiz, J. V., Izmaylov, A. F., Sonnenberg, J. L., Williams, Ding, F., Lipparini, F., Egidi, F., Goings, J., Peng, B., Petrone, A., Henderson, T., Ranasinghe, D., Zakrzewski, V. G., Gao, J., Rega, N., Zheng, G., Liang, W., Hada, M., Ehara, M., Toyota, K., Fukuda, R., Hasegawa, J., Ishida, M., Nakajima, T., Honda, Y., Kitao, O., Nakai, H., Vreven, T., Throssell, K., Montgomery Jr., J. A., Peralta, J. E., Ogliaro, F., Bearpark, M. J., Heyd, J. J., Brothers, E. N., Kudin, K. N., Staroverov, V. N., Keith, T. A., Kobayashi, R., Normand, J., Raghavachari, K., Rendell, A. P., Burant, J. C., Iyengar, S. S., Tomasi, J., Cossi, M., Millam, J. M., Klene, M., Adamo, C., Cammi, R., Ochterski, J. W., Martin, R. L., Morokuma, K., Farkas, O., Foresman, J. B., and Fox, D. J. (2016) Gaussian 16, revision A.03, Gaussian, Inc., Wallingford, CT.

(14) Hense, A., Herman, E., Oldemeyer, S., and Kottke, T. (2015) Proton Transfer to Flavin Stabilizes the Signaling State of the Blue Light Receptor Plant Cryptochrome, J. Biol. Chem. 290, 1743-1751.

(15) Hienerwadel, R., Boussac, A., Breton, J., Diner, B. A., and Berthomieu, C. (1997) Fourier transform infrared difference spectroscopy of photosystem II tyrosine D using site-directed mutagenesis and specific isotope labeling, Biochemistry 36, 14712-14723. 